\title{
Review
}

\section{Cytoskeletal Regulation of Epithelial Barrier Function During Inflammation}

\author{
Andrei I. Ivanov, ${ }^{*}$ Charles A. Parkos, ${ }^{\dagger}$ \\ and Asma Nusrat ${ }^{\dagger}$ \\ From the Gastroenterology and Hepatology Division, ${ }^{*}$ the \\ Department of Medicine, University of Rochester, Rochester, New \\ York; and the Epithelial Pathobiology Research Unit, ${ }^{\dagger}$ the \\ Department of Pathology and Laboratory Medicine, Emory \\ University, Atlanta, Georgia
}

Increased epithelial permeability is a common and important consequence of mucosal inflammation that results in perturbed body homeostasis and enhanced exposure to external pathogens. The integrity and barrier properties of epithelial layers are regulated by specialized adhesive plasma membrane structures known as intercellular junctions. It is generally believed that inflammatory stimuli increase transepithelial permeability by inducing junctional disassembly. This review highlights molecular events that lead to disruption of epithelial junctions during inflammation. We specifically focus on key mechanisms of junctional regulation that are dependent on reorganization of the perijunctional F-actin cytoskeleton. We discuss critical roles of myosin-II-dependent contractility and actin filament turnover in remodeling of the F-actin cytoskeleton that drive disruption of epithelial barriers under different inflammatory conditions. Finally, we highlight signaling pathways induced by inflammatory mediators that regulate reorganization of actin filaments and junctional disassembly in $\mathrm{mu}$ cosal epithelia. (Am J Patbol 2010, 177:512-524; DOI: 10.2353/ajpath.2010.100168)

The epithelium plays an important role in inflammation by serving as an interface between invading pathogens and the immune system of the host. Under physiological conditions, polarized epithelia form a protective barrier that allows regulated paracellular fluxes of solutes and nutrients as well as antigen sampling and surveillance by mucosal immune cells. However, during inflammation, this protective mechanism becomes compromised by various stimuli that originate on both sides of the epithelial barrier. On the apical (luminal) side, invading pathogenic microorganisms increase epithelial permeability to gain access into host tissue. The pathogens release a variety of epithelial barrier-disrupting agents that include poreforming toxins, cytoskeleton-modifying proteins, and bacterial lipopolysaccharide (LPS). On the basal (tissue) side of the epithelial layer, activated immune cells also induce barrier disruption to facilitate their movement to sites of pathogen invasion. Mucosal immune cells increase epithelial permeability by secreting proinflammatory cytokines such as interferon (IFN) $\gamma$, tumor necrosis (TNF) $\alpha$, and interleukin (IL) $-1 \beta$ or by releasing proteases and reactive oxygen species (ROS). As a result, mucosal inflammation commonly leads to sustained epithelial barrier compromise, which increases body exposure to external noxious agents, thereby further exaggerating the inflammatory response. Consequently it is believed that decreasing epithelial permeability may have beneficial effects by limiting inflammatory responses. Thus, understanding mechanisms that control the epithelial barrier disruption is important in identifying novel molecular targets for pharmacological modulation of mucosal inflammation.

Properties of the epithelial barrier are regulated by specialized plasma membrane structures referred to as apical junctions. These structures are composed of adhesive and scaffolding proteins that are anchored into different cytoskeletal structures such as actin filaments, intermediate filaments, and microtubules. During inflammation, it is known that reorganizations of apical junctions mediate epithelial barrier dysfunction. Mounting evidence suggests that the actin cytoskeleton plays a pivotal role in regulating junctional integrity and remodeling under physiological and pathological states.

In this review, we will discuss the role of actin filaments in the regulation of epithelial barrier integrity and its

\footnotetext{
Supported by a Senior Research Award from Crohn's and Colitis Foundation of America (A.I.I.) and by National Institutes of Health grants DK61379 and DK64399 (C.A.P.) and DK59888 and DK55679 (A.N.).

Accepted for publication April 19, 2010.

Address reprint requests to Andrei I. Ivanov, Ph.D., Gastroenterology and Hepatology Division, Department of Medicine, University of Rochester Medical Center, 601 Elmwood Avenue, Box 646, Rochester, NY 14642. E-mail: Andrei_Ivanov@urmc.rochester.edu.
} 
breakdown during inflammation. How inflammatory processes in different mucosal tissues induce remodeling of junction-associated filaments (F) actin and alter structure and barrier properties of epithelial cell-cell adhesions will be discussed. While epithelial junctions will be the major focus of this review, we will occasionally refer to examples of junctional regulation in the vascular endothelium. Likewise, we limit the discussion to simple columnar epithelia and exclude complex stratified epithelia such as the epidermis. Finally, we specifically focus on the role of actin filaments in maintenance and disassembly of epithelial junctions without discussing junctional reassembly during epithelial wound healing.

\section{Molecular Composition of Epithelial Apical Junctions and Organization of the Perijunctional Actin Cytoskeleton}

The simple epithelial lining of the gastrointestinal, respiratory, renal, and reproductive tracts is composed of a monolayer of polarized epithelial cells attached to their neighbors via highly organized intercellular junctions. These adhesive structures include tight junctions (TJs), adherens junctions (AJs), desmosomes, and gap junctions. ${ }^{1}$ The most apically located TJs and AJs are collectively referred to as the apical junctional complex (AJC), and it is generally believed that the AJC plays key roles in formation and maintenance of the epithelial barrier. Both TJs and AJs are composed of transmembrane and peripheral membrane protein complexes. ${ }^{1-3}$ The transmembrane proteins interact with their partners on the opposing plasma membrane, thereby providing a mechanical link between epithelial cells and establishing a barrier to paracellular diffusion of fluid and solutes. The peripheral membrane proteins form the so-called 'cytosolic plaque' of TJs and AJs, where they cluster and stabilize adhesive components of the AJC. Key transmembrane TJ proteins include occludin, members of the claudin family, and junctional adhesion molecule (JAM)-A. ${ }^{1,2}$ E-cadherin and members of the nectin family represent the major transmembrane proteins of epithelial AJs. ${ }^{2,3}$ The most studied constituents of the TJ cytosolic plaque are zonula occludens (ZO) proteins, afadin, and cingulin, which mediate interactions between different types of transmembrane proteins and/or link them to underlying actin filaments. ${ }^{1,2}$ The cytosolic plaque of the AJ includes two armadillo family proteins, $\beta$-catenin and p120 catenin, which interact with the intracellular domain of E-cadherin, and the actin-binding proteins $\alpha$-catenin, vinculin, and $\alpha$-actinin, which are likely to connect E-cadherin and the actin cytoskeleton via yet to be defined mechanisms. ${ }^{2,3}$

The apical region of polarized epithelial cells is rich in actin filaments and nonmuscle myosin II (NMII) that are assembled into several structures (Figure 1). ${ }^{4,5}$ These structures have been extensively studied in the brush border of vertebrate intestinal epithelium, where they are classified as microvillar F-actin bundles, an underlying terminal web that represents a meshwork of actin filaments cross-linking microvillar rootlets and the perijunc-

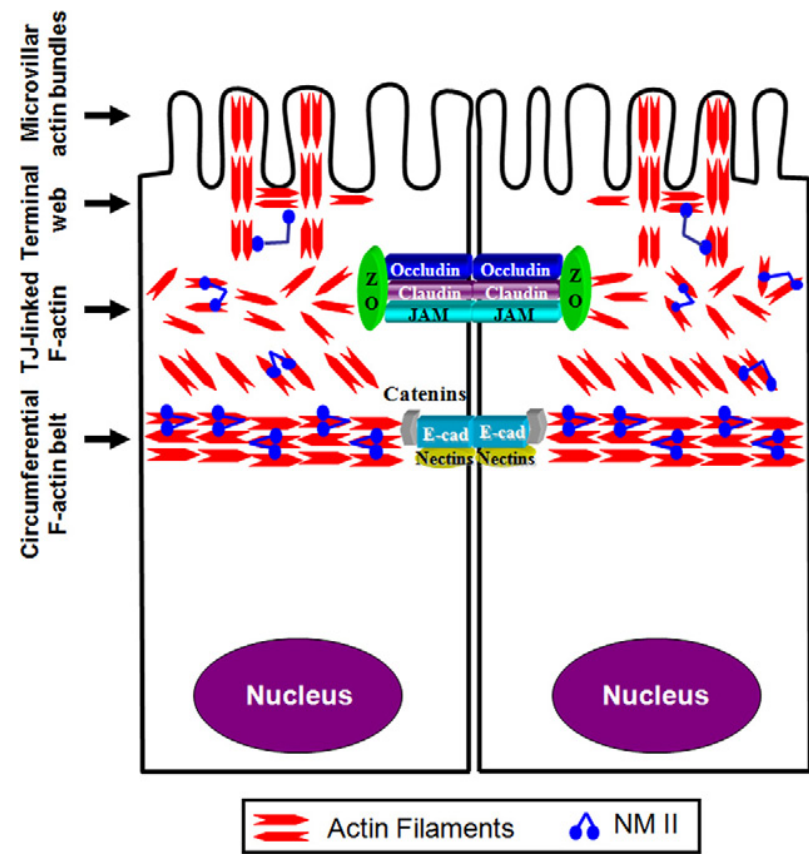

Figure 1. Organization of the apical actin cytoskeleton in polarized epithelia. The apical actin cytoskeleton in polarized epithelial cells consists of several interconnecting structures that include apical microvillar actin bundles, terminal web, actomyosin meshwork associated with tight junctions, and the circumferential actomyosin belt connected to adherens junctions. Reproduced and modified with permission from Ivanov. ${ }^{10}$

tional F-actin bundles. ${ }^{4,5} \mathrm{~A}$ prominent feature of the perijunctional cytoskeleton is a thick circumferential belt composed of bipolar actin filaments. This F-actin belt is oriented parallel to the plasma membrane at the level of AJs and appears to be physically associated with this junctional complex (Figure 1). ${ }^{6}$ Furthermore, a dense meshwork of F-actin bundles affiliated with TJs is positioned above the circumferential F-actin belt. ${ }^{7}$ Importantly, the circumferential F-actin belt can be co-isolated with other components of the brush border cytoskeleton and it demonstrates ATP dependent contractility ex vivo. ${ }^{6}$ These observations highlight the contractile nature of the apical Factin cytoskeleton and the intimate association between its components. The importance of actin filaments for integrity of the epithelial barrier has long been recognized. Some of the first reports observed increased paracellular permeability in Necturus gallbladder epithelium ${ }^{8}$ and guinea pig ileal mucosa ${ }^{9}$ after F-actin depolymerization by fungal toxins, cytochalasins. Subsequent pharmacological and genetic studies highlighted a key role of the actin cytoskeleton in regulating normal AJC structure as well as junctional remodeling in different experimental conditions. ${ }^{10,11}$

\section{Disruption of the Epithelial Barrier in Inflammation}

\section{Intestinal Epithelial Barrier}

Increased epithelial permeability is a well-accepted consequence of mucosal inflammation. This phenomenon has been extensively studied in the gut, where a leaky 
intestinal barrier is considered an important contributor to the pathophysiology of inflammatory bowel disease (IBD), which includes both Crohn's disease (CD) and ulcerative colitis $(U C) .^{12,13}$ Indeed, a decline in barrier function of the intestinal epithelium has been shown to positively correlate with the degree of mucosal inflammation in CD and UC patients. ${ }^{14}$ Furthermore, increased epithelial permeability precedes clinical relapse of $C D,{ }^{15}$ and healthy first-degree relatives of $C D$ patients have increased permeability across the intestinal epithelium. ${ }^{16}$ Recent animal model studies have demonstrated that colitis can be initiated by specific defects of the intestinal epithelium in the presence of normal immune responses and normal microbial flora. ${ }^{17}$ Conversely, pharmacological enhancement of the intestinal epithelial barrier was shown to significantly ameliorate mucosal inflammation in a spontaneous colitis-prone mice. ${ }^{18}$

A defective intestinal epithelial barrier is not unique to $\mathrm{IBD}$, because increased permeability of the gut has been well-documented in other immune-mediated enteropathies such as celiac disease, food allergies, and infection with various enteric pathogens. ${ }^{19,20}$ Furthermore, dysfunction of the intestinal epithelial barrier has also been implicated in pathogenesis of extraintestinal inflammatory disorders such as sepsis, type I diabetes, and ankylosing spondylosis. ${ }^{19,20}$ Increased intestinal permeability may pose a particular danger for patients with septic shock, due to massive translocation of luminal bacteria. ${ }^{21}$ Not surprisingly, the gut has been called a 'motor' or the 'undrained abscess' of multiple organ failure. ${ }^{22}$

\section{Respiratory Epithelial Barrier}

Similar to intestinal mucosa, the airway epithelium creates a protective physical barrier against inhaled microorganisms, allergens, and particles while also communicating with underlying immune and mesenchymal cells within the bronchial wall. ${ }^{23,24}$ Increased permeability across the airway epithelial barrier is an emerging contributor to pathogenesis of respiratory inflammation. Although permeability properties of respiratory epithelia in human disease remains poorly characterized, a number of studies with animal models of airway inflammation and cultured epithelial cell monolayers have demonstrated that inflammatory cytokines, bacterial products, and (ROS) disrupt integrity of the pulmonary epithelial barrier. ${ }^{25-27}$ Such barrier dysfunction likely contributes to the pathogenesis of airway disorders such as asthma and acute lung failure. ${ }^{28,29}$ Defective epithelial barrier can accelerate water influx into the lung leading to pulmonary edema and also result in enhanced activation of the airway immune responses by inhaled pathogens and allergens.

\section{Other Epithelial Barriers}

In contrast to intestinal and airway epithelia, little is known about the effect of inflammation on the integrity and function of other mucosal barriers in vivo. However, given that epithelial barrier structure and regulation in different or- gan systems have many similarities, ${ }^{30}$ it is easy to envision that barrier dysfunction represents a common pathophysiological mechanism of mucosal inflammation. This notion is supported by a number of in vitro studies demonstrating that inflammatory cytokines such as IFN $\gamma$, $\mathrm{TNF} \alpha$, and IL-1 $\beta$, as well as bacterial LPS, increase permeability of different model epithelia including renal tubular epithelial cells, ${ }^{31,32}$ retinal epithelial cells, ${ }^{33}$ and bile duct cholangiocytes. ${ }^{34}$ We can therefore predict that disruption of the epithelial barrier contributes to the pathogenesis of inflammatory disorders such as acute renal failure, retinopathy, cholestasis, and pancreatitis.

\section{AJC Disassembly Mediates Breakdown of the Epithelial Barrier During Inflammation}

Diverse inflammatory stimuli that increase leakiness of the epithelial barrier also cause disassembly of apical junctions. ${ }^{13,31,35-37}$ Therefore, the disruption of AJC structure is likely to mediate epithelial barrier dysfunction during mucosal inflammation. This conclusion is supported by extensive immunocytochemistry data, which document stimulus-induced loss of the characteristic labeling pattern for different AJ/TJ proteins at cell-cell contact zones. ${ }^{13,31,35-37}$ Interestingly, epithelial TJs and AJs appear to have different sensitivity to different inflammatory agents. For example, IFN $\gamma$ and TNF $\alpha$ are known to selectively disrupt TJs without affecting AJ structure. ${ }^{38}$ By contrast, some bacterial products such as Bacteroidis fragilis enterotoxin can selectively disrupt AJs by cleaving E-cadherin. ${ }^{39}$ On the other hand, (ROS) have been shown to disassemble both TJ and AJ protein complexes. ${ }^{40}$ It is likely therefore that severity of junctional disassembly and epithelial barrier disruption can be determined by a repertoire of microbial products and endogenous mediators in the inflamed mucosa.

Defects in the organization of epithelial junctions have also been observed in animal models of inflammation and tissue biopsies from human patients with different mucosal diseases. For example, translocation of occludin and JAM-A from TJs into an intracellular compartment was observed in small intestine of mice with experimental T-cell-dependent intestinal inflammation, ${ }^{41}$ whereas loss of junctional ZO-1 labeling was seen in the colonic epithelium of mice with dextran sulfate sodium (DSS)-induced colitis. ${ }^{42}$ Furthermore, LPS-dependent sepsis and caerulein-induced pancreatitis in rats were found to induce rapid disorganizations of TJs in colonic epithelium ${ }^{43}$ and pancreatic ductal epithelium, ${ }^{44}$ respectively. These animal model data are in good agreement with several clinical studies, which demonstrated substantial loss of E-cadherin, occludin, ZO-1, JAM-A, and claudin-1 from the AJC in intestinal mucosa of $C D$ and UC patients. ${ }^{45-47}$ The redistribution of junctional proteins in the intestinal epithelium of IBD patients is consistent with major defects in TJ structure as identified by freeze-fracture electron microscopy. ${ }^{48}$ In addition to gastrointestinal disorders, loss of junctional localization of E-cadherin, ZO-1, and JAM-A was observed in inflamed bronchial epithelium of patients with asthma and 
cystic fibrosis. ${ }^{27,49}$ Based on the profound effects of inflammatory mediators on the AJC structure in different model epithelia in vitro it is predictable that junctional disassembly represents a common mechanism of epithelial barrier dysfunction observed in various inflamed tissues in vivo.

Studies in transgenic and knockout animals have provided strong supporting data that disruption of the epithelial barrier can trigger and/or exaggerate mucosal inflammation. Several studies demonstrated that defects in the AJ structure are sufficient to induce murine colitis. Thus, transgenic mice expressing adhesion-defective $\mathrm{N}$-cadherin in the gut acquired defects in cell-cell junctions and developed intestinal inflammation resembling Crohn's disease..$^{50}$ Similar loss of the epithelial barrier and mucosal inflammation was observed in the intestine of mice lacking an AJ scaffolding protein, p120 catenin (A. Reynolds, personal communication). Finally, development of spontaneous colitis has been also observed in protein tyrosine phosphatase sigma-deficient mice, which has been attributed to hyperphosphorylation of E-cadherin and $\beta$-catenin and AJ disassembly in the colonic epithelium. ${ }^{51}$

Unlike defective AJ structure, knockout of individual TJ proteins such as occludin and JAM-A has not been shown to induce spontaneous colitis. However, two recent studies revealed increased colonic epithelial permeability in JAM-A knockout mice ${ }^{52,53}$ that was accompanied by increased mucosal inflammation in the gut. ${ }^{52}$ Additionally, JAM-A-null animals demonstrated dramatically exaggerated inflammatory response and higher mortality during DSS-induced colitis compared with wildtype controls. ${ }^{52,53}$ The increased epithelial permeability, mucosal inflammation, and susceptibility to DSS colitis was mediated by depletion of epithelial JAM-A, because ablation of endothelial/hematopoetic cell-specific JAM-A expression did not affect permeability or intestinal inflammation. ${ }^{53}$ These studies provided some of the first direct evidence that a specific defect in an epithelial TJ structure induces a "leaky gut" with increased intestinal mucosal inflammation in vivo.

\section{Inflammatory Mediators Alter Organization of Actin Filaments Associated with Epithelial Apical Junctions}

Early data showing intimate association of apical F-actin bundles with epithelial junctions and rapid AJ/TJ disassembly by F-actin cytoskeleton-disrupting toxins inspired the hypothesis that reorganization of actin filaments can be responsible for the loss of apical junctions in inflamed epithelia. ${ }^{54} \mathrm{~A}$ number of in vitro studies have investigated effects of microbial toxins and inflammatory mediators on the organization of the epithelial F-actin cytoskeleton. These studies have demonstrated that inflammatory stimuli frequently alter structure of perijunctional F-actin in conjunction with AJC disassembly and identified two major types of $\mathrm{F}$-actin alterations. ${ }^{10}$ The first type involved reorganization of the perijunctional F-actin belt into different contractile structures such as apical rings, vacuoles, or stress fiber-like cables. These contractile F-actin structures have been observed in colonic and renal epithelial cell monolayers incubated with $\mathrm{IFN} \gamma^{55,56}$ or $\mathrm{TNF} \alpha{ }^{32}$ gastric epithelial cells exposed to Helicobacter pylori, ${ }^{57}$ and pulmonary epithelial cells subjected to hypoxia ${ }^{58}$ or treated with transforming growth factor (TGF) $-\beta^{59}$ A second form of F-actin reorganization, characterized by decreased perijunctional F-actin labeling and indicative of filament depolymerization, was observed in colonic epithelium exposed to Bacteroides fragilis toxin ${ }^{60}$ or astrovirus ${ }^{61}$ and in alveolar epithelial cells exposed to LPS. ${ }^{62}$ These distinct types of perijunctional F-actin reorganizations in vitro are likely to reflect activation of different stimulus-dependent mechanisms of actin filament remodeling.

In contrast to well-documented effects of inflammatory mediators on junction-associated actin filaments in model epithelial monolayers, little is known about reorganization of perijunctional F-actin during mucosal inflammation in vivo. For example, data obtained from intestinal mucosa of IBD patients appears to be conflicting with one study reporting epithelial TJ disassembly without alterations in F-actin morphology in colonic biopsies of CD and UC patients ${ }^{63}$ and another study observing disorganization of intestinal epithelial F-actin in active UC. ${ }^{64}$ Our unpublished immunofluorescence labeling data highlight association of occludin with thick circumferential F-actin bundles in normal human intestinal mucosa (Figure 2, arrows). Notably, disappearance of occludin from TJs is accompanied by a dramatic disassembly of the perijunctional F-actin belt in the intestinal mucosa of a CD patient (Figure 2, arrowheads). Furthermore, recent proteomic analysis of intestinal mucosal tissues obtained from animal models of colitis and IBD patients revealed that mucosal inflammation in vivo induces significant changes in the expression of epithelial actin itself and a number of actin-binding proteins. ${ }^{65}$ However, it remains to be shown whether such changes in cytoskeletal protein expression mediate the observed defect in the intestinal epithelial barrier during experimental and clinical inflammation.

\section{Cytoskeletal Mechanisms Controlling AJC Disassembly during Inflammation: Myosin II-Dependent Contractility}

\section{The Role of Myosin II Motor in Regulation of the Epithelial AJC}

Myosin II or conventional myosin is a principal cytoskeletal motor that converts the chemical energy of ATP hydrolysis into mechanical forces, thus mediating the static tension and contractility of actin filaments. ${ }^{66}$ Epithelial cells express NMII consisting of a hexamer of two heavy chains, two essential, and two regulatory light chains $(R L C)$. The heavy chains are responsible for all major properties of NM IIA motor including ATP hydrolysis, actin binding, and oligomerization into myofibrils. ${ }^{66}$ Activation of NM II requires phosphorylation of its RLC on either one (Ser19) or two (Thr18/Ser19) residues. Such phosphorylation forces heavy chains to adopt an extended rod-like conforma- 

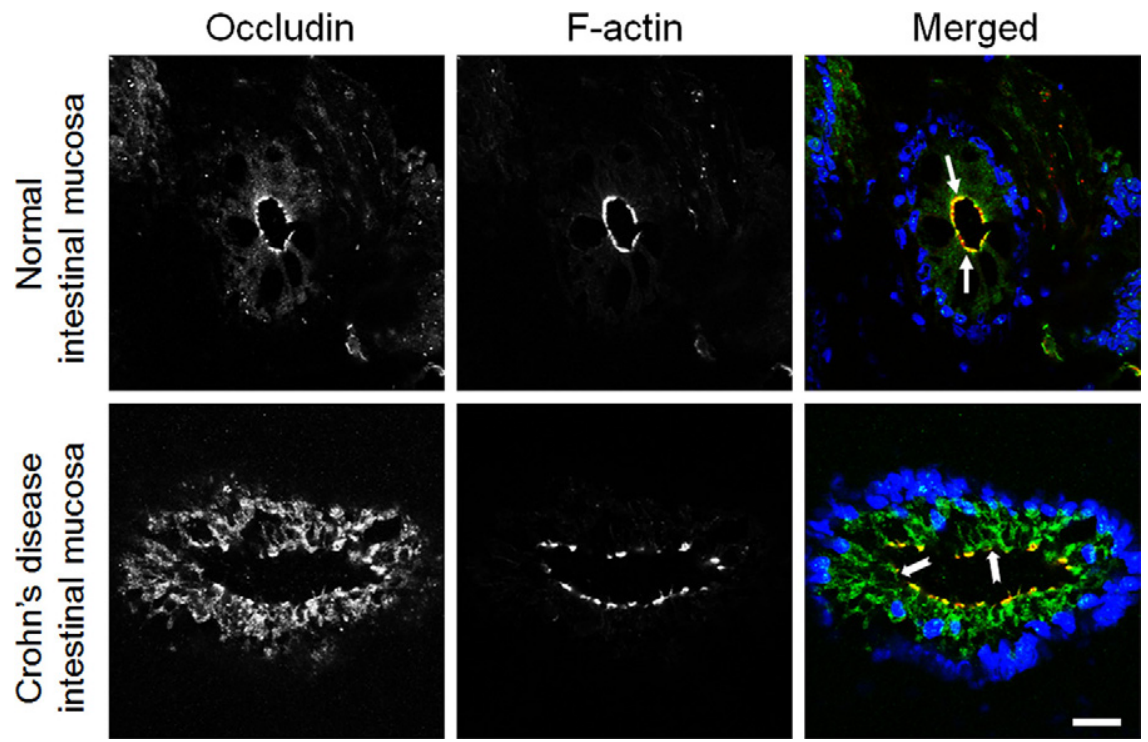

Figure 2. Mucosal inflammation in vivo induces orchestrated disruption of the perijunctional $\mathrm{F}$ actin belt and TJ disassembly. Tissue sections of colonic mucosa obtained from a normal human subject and a patient with active Crohn's disease were double-fluorescently labeled for occludin (green) and F-actin (red). Confocal microscopy images show significant colocalization (yellow) of occludin with the apical circumferential Factin belt in normal intestinal mucosa (arrows) By contrast, occludin is relocated from TJs into the cytoplasm and F-actin belt is disrupted (arrowhead) in the intestinal epithelium of Crohn's disease patient. Bar, $20 \mu \mathrm{m}$. tion, which enables actin filament binding and self-association of NM IIA. ${ }^{66}$

NM II is known to be enriched at the perijunctional F-actin belt, and a certain basal level of myosin phosphorylation and activity is necessary for the maintenance of junctional integrity. This notion is based on findings that NM II inhibition increases baseline paracellular permeability in model intestinal epithelial cell monolayers, ${ }^{67,68}$ whereas enhanced myosin RLC phosphorylation correlates with stimuli-induced increase in endothelial barrier tightness. ${ }^{69}$ On the other hand, it has been hypothesized that epithelial barrier breakdown in inflamed mucosa is driven by overactivation of NM II and increased contractility of the perijunctional actomyosin belt. ${ }^{13,36,70}$ However, review of published studies on this topic reveals that such role of actomyosin contractility has not been decisively proven in many studies of AJC disassembly induced by inflammatory mediators. It should be noted that extensive investigation of NM IIdriven processes such as cytokinesis and cell migration have established two major criteria that define involvement of myosin contractility in different cellular events. In particular, NM II-dependent contractile processes can be distinguished by the formation of specific actomyosin structures and by the sensitivity of such processes to inhibition of NM II motor activity with the only available pharmacological inhibitor blebbistatin.

Interestingly, relatively few studies addressing the role of actomyosin contractility in inflammation-dependent disruption of the epithelial AJC have focused of the NM II motor. For example, it was recently demonstrated that TJ disassembly in IFN $\gamma$-treated T84 human intestinal epithelial cells is driven by apical F-actin-coated vacuoles decorated with activated NM II. ${ }^{55}$ Inhibition of NM II motor with blebbistatin was shown to prevent IFN $\gamma$-dependent apical vacuolarization and TJ disassembly. Likewise, sufficient evidence supports the role of NM II-dependent contractility during disassembly of intercellular junctions in human pancreatic epithelial cells challenged with chemical activators of protein kinase $\mathrm{C}$ (PKC). ${ }^{71}$ In this system, PKC-induced junctional disassembly was accompanied by NM IIA translocation to contractile apical ring-like structures. Assembly of the contractile rings and junctional breakdown in pancreatic epithelial cells were attenuated by either pharmacological inhibition or siRNAmediated down-regulation of NM II motor. ${ }^{71}$ Formation of another type of contractile apparatus involving stress fibers was shown to correlate with junctional disassembly in bronchial epithelial cells treated with a combination of TGF- $\beta$ and environmental allergen. ${ }^{72}$ Inhibition of NM II with blebbistatin effectively prevented such cytoskeletal reorganization and disruption of epithelial cell-cell adhesions. The afore mentioned examples suggest that NM II-driven reorganization of the perijunctional F-actin belt is a common mechanism that mediates AJC disassembly triggered by various external stimuli. However, it remains to be investigated whether this mechanism is involved in epithelial barrier breakdown caused by other inflammatory mediators and pathogens.

Because there are three different NM II heavy chain isoforms, A, B and C, with distinct enzymatic properties and cellular functions in mammalian epithelia, ${ }^{10,66}$ it is important to establish which isoform(s) mediate regulation of TJ/AJ disassembly during inflammation. Several recent studies have implicated NM IIA as key regulator of epithelial junctions. In particular, quantitative mass spectroscopic analysis has revealed that NM IIA comprises a majority (65 to $85 \%$ ) of all NM II heavy chains in cultured human intestinal epithelial cells. ${ }^{73}$ In addition, selective siRNA-mediated depletion of NM IIA results in attenuated formation of contractile F-actin rings and AJC disassembly triggered by extracellular calcium depletion in a model intestinal epithelium. ${ }^{67}$ Selective siRNA-mediated knock-down of the two other NM II isoforms did not affect junctional disassembly in this model. Furthermore, PKC activation in human pancreatic epithelial cells, which do not express NM IIB, readily induced disruption of the AJC via stimulation of actomyosin contractility and siRNAmediated depletion of NM IIA effectively attenuated such junctional breakdown. ${ }^{71}$ Lastly, elimination of NM IIA but 
not NM IIB has been shown to inhibit thrombin-induced rounding of breast cancer cells, thus supporting a selective role of NM IIA in contractility of the epithelial cell cortex. $^{74}$

While regulation of epithelial junctions by NM II motor has been extensively investigated in model epithelial monolayers in vitro, no analogous in vivo studies have been reported. Using NM II inhibitor blebbistatin to examine myosin-dependent processes in animal models of inflammation is complicated by its poor solubility and instability in aqueous solution. Furthermore, genetic deletion of NM IIA in mice results in embryonic lethality. ${ }^{75}$ These observations suggest that studies on the role of NM II motor in the regulation of epithelial barrier function during mucosal inflammation in vivo will require using targeted deletion of NM IIA in different tissues

\section{The Roles of Rho/ROCK Signaling in NM II-Dependent Disassembly of the AJC}

Because actomysin contractility is regulated via multiple signaling mechanisms, ${ }^{66,76}$ substantial efforts have been devoted to elucidate the inflammatory signaling cascades that are responsible for activation of epithelial NM II. This question has important therapeutic implications because upstream NM II-activating kinases rather than myosin II motor are attractive targets for the development of drugs that attenuate breakdown of epithelial barrier function. A majority of published studies have focused on two signaling pathways culminating in activation of either Rho-associated kinase (ROCK) or myosin light chain kinase (MLCK).

ROCK is known to increase the activating phosphorylation of NM II RLC at Thr18 and Ser19 residues either directly or by inactivating myosin light chain phosphatase. ${ }^{66,76}$ ROCK-dependent phosphorylation of NM IIA is considered an important regulator of different contractile processes in adherent cells including generation of traction forces ${ }^{77}$ and retraction of the trailing edge during cell migration. ${ }^{78}$ Notably, ROCK has been shown to selectively phosphorylate RLC that is associated with the NM IIA heavy chain. ${ }^{74}$ Such selective coupling between ROCK and NM IIA may explain why ROCK is particularly important for NM II-dependent disassembly of epithelial junctions.

Several lines of evidence support the role of Rho/ ROCK signaling in stimulus-induced disruption of AJs and TJs in vitro. Specifically, Rho and ROCK have been observed to colocalize with intact or disassembling TJs in intestinal epithelial cell monolayers. ${ }^{79}$ Additionally, enhancing Rho activity by overexpression of its wild-type or constitutively active forms has been shown to induce AJ and TJ disassembly. ${ }^{80,81}$ Finally, disruption of the AJC by a number of pathogenic/inflammatory stimuli has been shown to be associated with increased activity of Rho and/or ROCK and is attenuated by Rho and ROCK inhibition. ${ }^{32,55,71,82,83}$ Importantly, several studies have directly compared effects of ROCK and MLCK inhibition on junctional breakdown induced by proinflammatory cytokines, ${ }^{55,83}$ PKC-activating tumor promoters, ${ }^{71}$ and cal- cium depletion. ${ }^{79}$ In these studies, inhibition of Rho/ ROCK but not MLCK signaling effectively attenuated AJC disassembly. These data suggest that Rho/ROCK signaling plays a key role in triggering the barrier breakdown in model epithelial cell monolayers. In support of this, ROCK inhibition has been shown to prevent epithelial inflammation in mouse models of colitis ${ }^{84}$ and LPS-induced renal failure. ${ }^{85}$ However, it remains to be shown whether these beneficial effects of ROCK inhibition in vivo are directly mediated by protective effect on the epithelial barrier.

Furthermore, accumulating evidence suggest that Rho/ROCK-NM II-dependent AJC disassembly in inflamed mucosa causes profound phenotypical changes in epithelial cells. These changes involve down-regulation of epithelia-specific genes and up-regulation of mesenchymal genes (such as smooth muscle actin) leading to the so called epithelial-to-mesenchymal and epithelialto-myofibroblast transitions. ${ }^{86,87}$ As a result, sustained activation of Rho/ROCK-mediated actomyosin contractility can contribute to the development of organ fibrosis and irreversible loss of mucosal epithelia during chronic inflammation.

Two isoforms of Rho kinase, ROCK-I and ROCK-II, are expressed in mammalian cells. Despite high homology ( $\sim 65 \%$ sequence identity), ROCK-I and ROCK-II are differentially regulated and may activate distinct actomyosin-dependent cellular processes. ${ }^{88}$ Interestingly, recent studies involving selective siRNA-mediated knock-down of these isoforms revealed a unique role for ROCK-II in TJ disassembly triggered by calcium depletion or PKC activation. ${ }^{71,79}$ These findings are consistent with data that ROCK-II but not ROCK-I expression and activity is readily upregulated by hormones and bacterial products. ${ }^{85,89}$ Such responsiveness of ROCK-II to external stimulation suggests that this isoform may play an important role in transducing inflammatory signals that disrupt the epithelial barrier.

How can inflammatory agents activate Rho/ROCK signaling cascade in epithelial cells? Two complementary mechanisms can be envisioned, one involving increased expression of ROCK and/or Rho and another involving stimulation of Rho activity by upstream GDP-GTP exchange factors (GEFs). Indeed, a significant increase in ROCK protein level that paralleled IFN $\gamma$-induced junctional disassembly in model colonic epithelial cell monolayers was reported. ${ }^{55}$ Likewise, induction of ROCK-II expression has been detected in mesenteric arteries of LPS-treated rats. ${ }^{90}$ An expression-independent mechanism of activation of Rho/ROCK signaling leading to junctional disassembly has been recently described in kidney proximal tubular cells challenged with $\mathrm{TNF} \alpha{ }^{32}$ In this system TNF $\alpha$ induced phosphorylation and activation of GEF-H1 thereby stimulating the Rho signaling pathway. Furthermore, activation of GEF-H1 by TJ-disrupting enteropathogenic E. coli ${ }^{91}$ and Shigella flexneri ${ }^{92}$ has been observed. On the other hand, GEF-H1 is known to accumulate at epithelial $\mathrm{TJs}^{79,93}$ and to be involved in junctional disassembly. ${ }^{79}$ Together these data highlight the GEH-H1-Rho-ROCK signaling cascade as key mediator of junctional disassembly induced by inflammatory mediators and pathogens (Figure 3). 


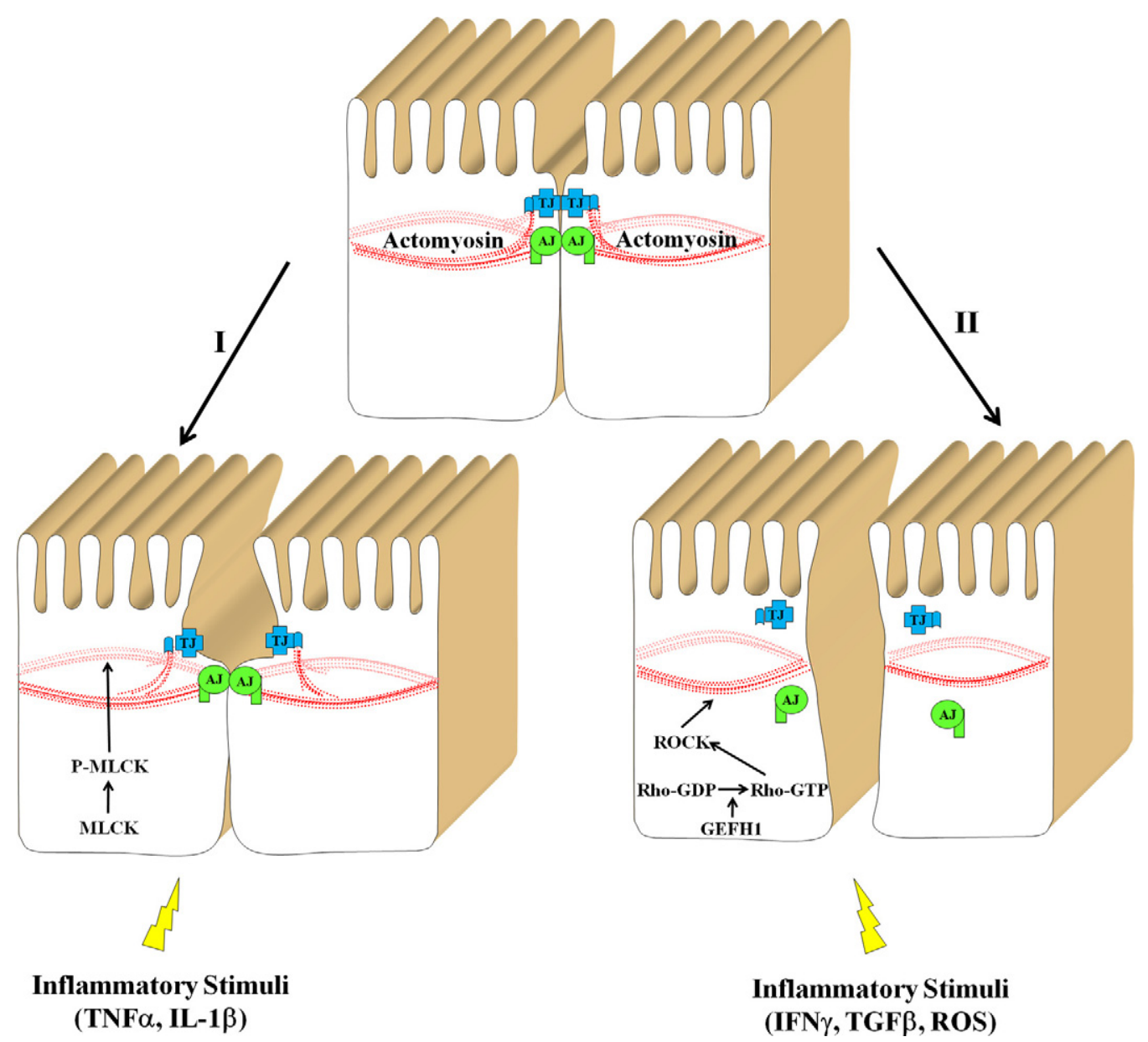

Figure 3. Signaling pathways that mediate actomyosin-dependent disruption of the epithelial barrier in inflammation. Two signaling pathways that are activated by different inflammatory stimuli and result in disruption of the epithelial barrier are presented. The first pathway involves activation of MLCK resulting in a modest contraction of perijunctional actomyosin belt and reversible increase in paracellular permeability without gross alterations in AJC structure. The second pathway involves activation of the GEF-H1-Rho-ROCK pathway that leads to profound actomyosin contraction and AJC disassembly.

\section{MLCK Signaling and AJC Disassembly in Inflammatory Conditions}

MLCK-induced contractility of the perijunctional actomyosin belt is considered as another important mechanism underlying disruption of the epithelial barrier during inflammation. ${ }^{13,36}$ For example, MLCK activation has been implicated in disruption of AJC in intestinal epithelium induced by $\mathrm{TNF} \alpha,{ }^{94} \mathrm{IL}-1 \beta,{ }^{95}$ and lympotoxin-like inducible protein. ${ }^{96}$ Likewise, this mechanism has been shown to be important for LPS-induced disruption of the paracellular barrier in intestinal and pulmonary epithelia ${ }^{43,97}$ as well as in cholangiocyte monolayers. ${ }^{34}$ Furthermore, TJ disassembly triggered by gastrointestinal pathogens such as Helicobacter pylori or Giardia is considered to be mediated by MLCK. ${ }^{98-100}$ Despite the extensive literature implicating MLCK in the disruption of the epithelial barrier, evidence supporting this signaling mechanism remains controversial and incomplete. In particular, many studies addressing the role of MLCK in junctional regulation have relied on a single class of MLCK inhibitors such as ML-7 and ML-9. ${ }^{34,43,95,97,98,100}$ While inhibiting MLCK, these ATP-competitive agents also inactivate other kinases. ${ }^{101} \mathrm{ML}-9$, for example, has been shown to inhibit ROCK-II activity more potently than MLCK. ${ }^{101} \mathrm{Be}-$ cause a majority of studies involving ML-7 and/or ML-9 have not included alternative strategies such as blockage of Rho/Rock pathways or NM-II motor, the results from such reports may have been influenced by inhibition of other signaling pathways. Additional studies using complementary specific inhibition would help to clarify these questions.

In another series of studies, blockade of MLCK activity with a selective peptide inhibitor PIK has been shown to attenuate the increase in permeability of colonic epithelial cell monolayers induced by proinflammatory cytokine treatment or enteropathogenic E. coli infection. ${ }^{96,102}$ However, it has not been reported whether PIK can prevent cytokine- or pathogen-dependent disruption of TJ structure in model epithelia in vitro. While treatment with PIK has been shown to attenuate increased intestinal epithelial permeability and TJ disassembly in a T-cell activation model of colitis, ${ }^{41}$ it failed to prevent mucosal barrier disruption in DSS-induced colitis. ${ }^{103}$ These data suggest that MLCK-dependent and independent mechanisms can mediate barrier disruption during mucosal inflammation in vivo. Lastly, if MLCK was the primary kinase regulating AJC disassembly during inflammation, 
then its sustained activation would be expected to induce disruption of TJs and/or AJs. However, expression of constitutively active MLCK in Caco-2 intestinal epithelial cells has been shown to result in approximately $20 \%$ decreases in transepithelial electrical resistance without significant effects on the TJ integrity. ${ }^{94}$ Likewise, transgenic mice expressing constitutively active MLCK in the intestinal epithelium have a modest increase in paracellular permeability along with normal TJ structure. ${ }^{104}$ The apparent lack of effect of MLCK activation on junctional structure contrasts sharply with the consequences of Rho activation, which have been shown to induce dramatic disassembly of AJs and TJs. ${ }^{80,81}$ Overall, these data indicate that Rho/ROCK and MLCK signaling can modulate epithelial barrier during inflammation, however activation of these two pathways has different effects on the epithelial AJC. As highlighted in Figure 3, stimulation of MLCK activity results in transient increase in the barrier permeability without inducing dramatic reorganization of the apical cytoskeleton and defects of TJ structure. By contrast, activation of Rho/ROCK pathway triggers contraction of the perijunctional F-actin belt that drives TJ disassembly and increase in paracellular permeability. MLCK and Rho/ROCK pathways can be either selectively induced by different inflammatory stimuli or can be coinduced and act together. In the latter scenario, MLCK activation may cause initial loosening of the paracellular barrier, which is then followed by Rho/ROCK-dependent junctional disassembly.

\section{Cytoskeletal Mechanisms Controlling AJC Disassembly during Inflammation: F-Actin Turnover}

\section{Role of Filament Turnover in Remodeling of the Actin Cytoskeleton}

Actin filaments are self-assembling polymers of actin, which have different dynamic properties at the filament ends. ${ }^{105}$ The barbed end of the filament grows rapidly, whereas the filament readily disassembles into subunits from the opposite pointed end. A simplified model of F-actin turnover implies that actin monomers are constantly removed from the pointed end to be added to the barbed end of the filament ${ }^{105}$ (Figure 4). This process, which is also known as F-actin treadmilling, regulates filament length and movements and also creates forces for pushing and pulling intracellular membranes and organelles. ${ }^{106}$ Of note, filament treadmilling is a prominent feature of the perijunctional F-actin belt that has been observed by incorporation of fluorescently-labeled monomeric actin. ${ }^{107}$ Furthermore, inhibition of F-actin turnover by treatment with an actin monomer-sequestering drug has been shown to induce disassembly and internalization of TJs. ${ }^{108}$ Both treadmilling and myosin IIdependent contractility appear to be complementary and interdependent mechanisms of F-actin reorganization. Indeed, recent data indicate that NM II can control the rate of F-actin turnover by stimulating filament breakdown. ${ }^{109}$

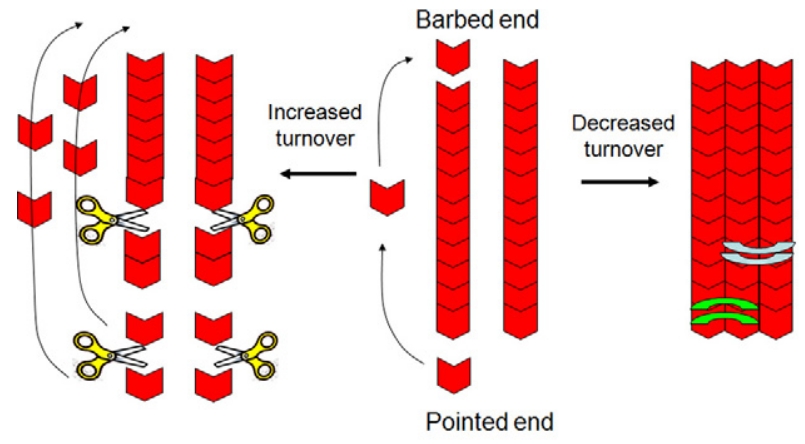

$D-$ Actin $\mathrm{o} s-A D F / C o f i l i n \rightleftharpoons-$ Eplin $\rightleftharpoons-\alpha$-Actinin

Figure 4. Regulation of actin filament turnover. The Figure presents a simplified model of actin filament turnover and shows two mechanisms regulating the velocity of this process. The increased F-actin turnover can be mediated by actin-depolymerizing factor (ADF)/cofilin-driven F-actin depolymerization, whereas decreased turnover can be achieved by eplin and/or actinin-dependent filament cross-linking.

Similarly, F-actin turnover has been shown to be essential for NM II-mediated contractility. ${ }^{110}$ It is thus reasonable to suggest that F-actin treadmilling and actomyosin contractility cooperate in reorganizing the perijunctional Factin belt and driving junctional disassembly during inflammation. One can envision a number of reasons for the interdependence of these two processes. For example, the perijunctional F-actin belt that supports mature epithelial junctions could be too rigid to allow substantial contraction and would become "loosened" by increased F-actin turnover. In addition, treadmilling could be important for altering actin filament alignment to facilitate more efficient NM II-mediated contraction. Finally, contractile F-actin structures associated with disassembling AJC are transient in nature and require disassembly via F-actin depolymerization.

Relatively little is known about the involvement of $\mathrm{F}$ actin turnover in disassembly of epithelial junctions. For instance, pharmacological inhibition of this process by F-actin-stabilizing drug jasplakinolide has been shown to attenuate AJC disassembly in model intestinal and renal epithelia caused by either calcium depletion ${ }^{68}$ or PKC activation. ${ }^{111}$ In contrast, increased F-actin treadmilling did not appear to play a role in the formation of contractile F-actin structures that mediated TJ disassembly in IFN $\gamma$-treated colonic epithelial cells. ${ }^{55}$ Notably, many inflammatory stimuli such as ROS ${ }^{112}$ and bacterial toxins ${ }^{113}$ are known to induce depolymerization of epithelial F-actin, which can be due to the increase in F-actin turnover. Hence, accelerated Factin treadmilling is likely to be important for AJC disassembly, although additional studies are needed to elucidate the roles for this mechanism in dysfunctions of the epithelial barrier during inflammation.

\section{Role of Actin-Depolymerizing Factor/Cofilin Proteins in Remodeling of the AJC}

Accelerated F-actin turnover that controls disassembly of the epithelial AJC in inflamed mucosa can be mediated 
by the increased velocity of filament depolymerization (Figure 4). In mammalian cells, breakdown of actin filaments is controlled primarily by proteins of the actindepolymerizing factor (ADF)/cofilin family ${ }^{114,115}$ that consists of three members: ADF, cofilin-1, and cofilin-2. These three proteins are encoded by different genes and have distinct expression patterns. In particular, cofilin-2 expression is restricted to muscle cells, where as ADF is abundantly expressed in epithelia. The activity of ADF and cofilins is regulated by phosphorylation at a conserved N-terminal Ser3 residue that decreases ADF/cofilin ability to bind and depolymerize F-actin. ${ }^{114}$ Therefore, phosphorylation/dephosphorylation acts as a simple 'on' and 'off' switch for F-actin disassembly. The cellular level of phosphorylated (inactive) ADF/cofilin is regulated by a balance between activity of LIM domain kinases (LIMK; $\left.{ }^{116}\right)$ and Slingshot phosphatases. ${ }^{117}$ An alternative, phosphorylation-independent regulator of ADF/cofilin functions involves binding to a special scaffold, actininteracting protein-1. ${ }^{114}$ This protein is known to enhance ADF/cofilin-dependent filament severing and it can also coordinate the entire cycle of F-actin treadmilling by modulating activity of actin-polymerizing proteins such as coronins and profilin. ${ }^{114}$

Roles of ADF/cofilin-1 in the remodeling of AJC and the development of inflammation remain poorly understood and somewhat controversial. For example, these proteins become activated after disruption of intestinal epithelial barrier function by either calcium depletion ${ }^{68}$ or capsaicin treatment. ${ }^{118}$ Furthermore, overexpression of constitutively-active cofilin accelerates capsaicin-dependent barrier breakdown. ${ }^{118}$ Likewise, dramatic activation of $\mathrm{ADF} /$ cofilin parallels disassembly of the apical F-actin cytoskeleton in ATP-depleted cultured renal epithelial cell monolayers ${ }^{119}$ and in the rat proximal tubule epithelium during experimentally induced renal ischemia in vivo. ${ }^{120}$ Expression of a constitutively-active ADF/cofilin mutant augmented disruption of such apical F-actin in ATP-depleted cell, whereas inactive ADF/cofilin mutant prevented this process. ${ }^{119}$ Collectively, these observations suggest that activation of ADF/cofilin destabilizes the apical F-actin cytoskeleton and therefore can trigger disassembly of epithelial junctions. Because proinflammatory cytokines are known to up-regulate cofilin expression and decrease its phosphorylation, ${ }^{121}$ stimulation of ADF/ cofilin-dependent actin turnover is a reasonable mechanism for epithelial barrier disruption during inflammation. Interestingly, other recent studies have suggested that dysfunction of ADF/cofilin can negatively regulate cellcell adhesions and promote inflammation. For example, overexpression of LIMK1, which inactivates ADF/cofilin, has been shown to increase permeability of endothelial cell monolayers and disrupt endothelial junctions. ${ }^{122}$ Furthermore, LIMK1 deficiency in mice significantly decreased severity of LPS-induced acute lung injury by suppressing microvascular permeability and neutrophil infiltration in the lungs. ${ }^{122}$ Additionally, ADF-deficient mice have been shown to develop spontaneous inflammation of the cornea. ${ }^{123}$ These apparently contradictory sets of data can be reconciled if it is assumed that intermediate levels of perijunctional actin filament turn- over are required for the integrity of the epithelial barrier. Under this scenario, increased rates of treadmilling would lead to F-actin depolymerization and junctional disassembly, whereas diminished rates of F-actin treadmilling would result in excessive F-actin polymerization, aberrant architecture of perijunctional actin-filaments, and defective AJ/TJ structure. Another possibility is that ADF/cofilin activity can be also critical for F-actin polymerization by generating new filament barbed ends. ${ }^{124}$ In the latter scenario, dysfunctions of ADF/cofilin may result in defective assembly of the perijunctional F-actin belt resulting in the impaired AJC structure. These hypotheses would explain why both overactivation and inactivation of ADF/cofilin have negative effects on barrier properties of epithelial junctions.

\section{Roles of Actin-Bundling Proteins in AJC Stability and Disassembly}

An additional mechanism that may regulate accelerated F-actin turnover and AJC disassembly during inflammation involves decreased actin filament cross-linking and bundling (Figure 4). ${ }^{125}$ Parallel actin bundles represent the most common type of cross-linked cytoskeletal structures in which filaments are aligned axially and are tightly packed together. ${ }^{126}$ Within these bundles the turnover rate of actin filaments is dramatically decreased. ${ }^{127}$ Thick parallel bundles have been shown to organize the circumferential F-actin belt that controls stability and barrier functions of epithelial junctions. ${ }^{4,5}$ Assembly of actin filaments into linear bundles is accomplished by specialized actin cross-linking proteins. ${ }^{125}$ These proteins possess multiple actin-binding sites, which allow them to link together adjacent filaments. Several actin-bundling proteins including $\alpha$-actinin, plastins, and eplin are enriched at epithelial junctions $4,5,128$ and may be essential in regulation of the epithelial AJC. For example, overexpression of a dominant-negative form of $\alpha$-actinin has been shown to disrupt AJs in renal epithelial cells, ${ }^{129}$ whereas siRNAmediated knockdown of $\alpha$-actinin-4 isoform delays reassembly of TJs in a mammary epithelium. ${ }^{130}$ Furthermore, depletion of eplin expression has been found to impair organization of the perijunctional F-actin belt and $A J$ integrity in vitro. ${ }^{128}$ Interestingly, plastin-1-deficient mice are characterized by increased permeability of the intestinal barrier in vivo, although no changes in epithelial TJ and AJ morphology have been detected in these animals. ${ }^{131}$

Virtually nothing is known about the role of actin-bundling proteins in epithelial barrier dysfunction during inflammation. However, mutations in the $\alpha$-actinin- 4 isoform have been associated with glomerulosclerosis in humans, ${ }^{132}$ and $\alpha$-actinin-4-null mice develop severe glomerular disease. ${ }^{133}$ In addition, increased sensitivity to DSS colitis has been observed in plastin-1-null mice. ${ }^{131}$ These data implicate F-actin cross-linking proteins in regulating the integrity of epithelial barriers in diseases. Interestingly, decreased mRNA expression of $\alpha$-actinins 1 and 4 has been detected in the intestinal mucosa of CD and UC patients. ${ }^{134}$ Such expressional down-regulation 
is likely to decrease actin filament bundling and increase their turnover rate in IBD mucosa. Another potential mechanism that destabilizes epithelial F-actin during inflammation involves a phosphorylation-dependent decrease in association of actin-bundling proteins with actin filaments such as observed after tyrosine phosphorylation of $\alpha$-actinin ${ }^{135}$ and serine phosphorylation of eplin. ${ }^{136}$ It remains to be investigated how expression and phosphorylation-dependent functional down-regulation of different $F$-actin cross-linking proteins contribute to the disruption of epithelial barriers during inflammation.

\section{Conclusion}

Substantial progress has been achieved recently in understanding structure and dynamics of epithelial junctions that has significantly improved our knowledge of how the epithelial barrier is regulated under normal physiological conditions and during inflammation. Remodeling of the actin cytoskeleton has emerged as a key mechanism that mediates junctional disassembly and breakdown of the epithelial barrier in inflamed tissues. Despite this progress, we still need better understanding of how the complexity of inflammatory signaling is integrated with the complexity of mechanisms controlling actin filament remodeling. Another future challenge will be to gain better insight into F-actindependent regulation of epithelial barrier function in inflamed tissues in vivo. Addressing these challenges will not only improve understanding fundamental mechanisms of inflammatory responses but will also help in the development of new therapeutic approaches aimed at preserving integrity of the epithelial barrier in different diseases.

\section{Acknowledgments}

We are grateful to Drs. Steve Georas and Nayden Naydenov for critical reading of the manuscript and Dr. Eric Severson for figure preparation.

\section{References}

1. Tsukita S, Furuse M, Itoh M: Multifunctional strands in tight junctions. Nat Rev Mol Cell Biol 2001, 2:285-293

2. Hartsock A, Nelson WJ: Adherens and tight junctions: structure, function and connections to the actin cytoskeleton. Biochim Biophys Acta 2008, 1778:660-669

3. Pokutta S, Weis WI: Structure and mechanism of cadherins and catenins in cell-cell contacts. Annu Rev Cell Dev Biol 2007, 23:237-261

4. Bretscher A: Microfilament structure and function in the cortical cytoskeleton. Annu Rev Cell Biol 1991, 7:337-374

5. Mooseker MS: Organization, chemistry, and assembly of the cytoskeletal apparatus of the intestinal brush border. Annu Rev Cell Biol 1985, 1:209-241

6. Hirokawa N, Keller TC, 3rd, Chasan R, Mooseker MS: Mechanism of brush border contractility studied by the quick-freeze, deep-etch method. J Cell Biol 1983, 96:1325-1336

7. Madara JL: Intestinal absorptive cell tight junctions are linked to cytoskeleton. Am J Physiol 1987, 253:C171-C175

8. Bentzel CJ, Hainau B, Ho S, Hui SW, Edelman A, Anagnostopoulos T, Benedetti EL: Cytoplasmic regulation of tight-junction permeability: effect of plant cytokinins. Am J Physiol 1980, 239:C75-C89
9. Madara JL, Barenberg D, Carlson S: Effects of cytochalasin D on occluding junctions of intestinal absorptive cells: further evidence that the cytoskeleton may influence paracellular permeability and junctional charge selectivity. J Cell Biol 1986, 102:2125-2136

10. Ivanov Al: Actin motors that drive formation and disassembly of epithelial apical junctions. Front Biosci 2008, 13:6662-6681

11. Miyoshi J, Takai Y: Structural and functional associations of apical junctions with cytoskeleton. Biochim Biophys Acta 2008, 1778: 670-691

12. Kucharzik T, Maaser C, Lugering A, Kagnoff M, Mayer L, Targan S, Domschke W: Recent understanding of IBD pathogenesis: implications for future therapies. Inflamm Bowel Dis 2006, 12:1068-1083

13. Turner JR: Intestinal mucosal barrier function in health and disease. Nat Rev Immunol 2009, 9:799-809

14. Murphy MS, Eastham EJ, Nelson R, Pearson AD, Laker MF: Intestinal permeability in Crohn's disease. Arch Dis Child 1989, 64:321-325

15. Wyatt J, Vogelsang H, Hubl W, Waldhoer T, Lochs H: Intestinal permeability and the prediction of relapse in Crohn's disease. Lancet 1993, 341:1437-1439

16. Katz KD, Hollander D, Vadheim CM, McElree C, Delahunty T, Dadufalza VD, Krugliak P, Rotter JI: Intestinal permeability in patients with Crohn's disease and their healthy relatives. Gastroenterology 1989, 97:927-931

17. Van der Sluis M, De Koning BA, De Bruijn AC, Velcich A, Meijerink JP, Van Goudoever JB, Buller HA, Dekker J, Van Seuningen I, Renes IB, Einerhand AW: Muc2-deficient mice spontaneously develop colitis, indicating that MUC2 is critical for colonic protection. Gastroenterology 2006, 131:117-129

18. Arrieta MC, Madsen K, Doyle J, Meddings J: Reducing small intestinal permeability attenuates colitis in the IL10 gene-deficient mouse. Gut 2009, 58:41-48

19. Cereijido M, Contreras RG, Flores-Benitez D, Flores-Maldonado C Larre I, Ruiz A, Shoshani L: New diseases derived or associated with the tight junction. Arch Med Res 2007, 38:465-478

20. Groschwitz KR, Hogan SP: Intestinal barrier function: molecular regulation and disease pathogenesis. J Allergy Clin Immunol 2009, 124:3-20

21. Fink MP, Delude RL: Epithelial barrier dysfunction: a unifying theme to explain the pathogenesis of multiple organ dysfunction at the cellular level. Crit Care Clin 2005, 21:177-196

22. Marshall JC, Christou NV, Meakins JL: The gastrointestinal tract. The "undrained abscess" of multiple organ failure. Ann Surg 1993, 218:111-119

23. Holgate ST: Epithelium dysfunction in asthma. J Allergy Clin Immunol 2007, 120:1233-1244

24. Knight DA, Holgate ST: The airway epithelium: structural and functional properties in health and disease. Respirology 2003, 8:432-446

25. Boardman KC, Aryal AM, Miller WM, Waters CM: Actin re-distribution in response to hydrogen peroxide in airway epithelial cells. J Cell Physiol 2004, 199:57-66

26. Chignard M, Balloy V: Neutrophil recruitment and increased permeability during acute lung injury induced by lipopolysaccharide. Am J Physiol Lung Cell Mol Physiol 2000, 279:L1083-L1090

27. Coyne CB, Vanhook MK, Gambling TM, Carson JL, Boucher RC, Johnson LG: Regulation of airway tight junctions by proinflammatory cytokines. Mol Biol Cell 2002, 13:3218-3234

28. Lucas R, Verin AD, Black SM, Catravas JD: Regulators of endothelial and epithelial barrier integrity and function in acute lung injury. Biochem Pharmacol 2009, 77:1763-1772

29. Swindle EJ, Collins JE, Davies DE: Breakdown in epithelial barrier function in patients with asthma: identification of novel therapeutic approaches. J Allergy Clin Immunol 2009, 124:23-34

30. Gonzalez-Mariscal L, Tapia R, Chamorro D: Crosstalk of tight junction components with signaling pathways. Biochim Biophys Acta 2008, 1778:729-756

31. Capaldo CT, Nusrat A: Cytokine regulation of tight junctions. Biochim Biophys Acta 2009, 1788:864-871

32. Kakiashvili E, Speight P, Waheed F, Seth R, Lodyga M, Tanimura S, Kohno M, Rotstein OD, Kapus A, Szaszi K: GEF-H1 mediates tumor necrosis factor- $\alpha$-induced Rho activation and myosin phosphorylation role in the regulation of tubular paracellular permeability. J Biol Chem 2009, 284:11454-11466

33. Abe T, Sugano E, Saigo Y, Tamai M: Interleukin- $1 \beta$ and barrier 
function of retinal pigment epithelial cells (ARPE-19): aberrant expression of junctional complex molecules. Invest Ophthalmol Vis Sci 2003, 44:4097-4104

34. Sheth P, Delos Santos N, Seth A, LaRusso NF, Rao RK: Lipopolysaccharide disrupts tight junctions in cholangiocyte monolayers by a c-Src-. TLR4-, and LBP-dependent mechanism, Am J Physiol Gastrointest Liver Physiol 2007, 293:G308-G318

35. Gonzalez-Mariscal L, Garay E, Lechuga S: Virus interaction with the apical junctional complex. Front Biosci 2009, 14:731-768

36. O'Hara JR, Buret AG: Mechanisms of intestinal tight junctional disruption during infection. Front Biosci 2008, 13:7008-7021

37. Rao R: Oxidative stress-induced disruption of epithelial and endothelial tight junctions. Front Biosci 2008, 13:7210-7226

38. Bruewer M, Luegering A, Kucharzik T, Parkos CA, Madara JL, Hopkins AM, Nusrat A: Proinflammatory cytokines disrupt epithelial barrier function by apoptosis-independent mechanisms. J Immunol 2003, 171:6164-6172

39. Wu S, Lim KC, Huang J, Saidi RF, Sears CL: Bacteroides fragilis enterotoxin cleaves the zonula adherens protein, E-cadherin. Proc Natl Acad Sci USA 1998, 95:14979-14984

40. Rao RK, Basuroy S, Rao VU, Karnaky Jr KJ, Gupta A: Tyrosine phosphorylation and dissociation of occludin-ZO-1 and E-cadherin$\beta$-catenin complexes from the cytoskeleton by oxidative stress, Biochem J 2002, 368:471-481

41. Clayburgh DR, Barrett TA, Tang Y, Meddings JB, Van Eldik LJ, Watterson DM, Clarke LL, Mrsny RJ, Turner JR: Epithelial myosin light chain kinase-dependent barrier dysfunction mediates T cell activation-induced diarrhea in vivo. J Clin Invest 2005, 115: 2702-2715

42. Poritz LS, Garver KI, Green C, Fitzpatrick L, Ruggiero F, Koltun WA: Loss of the tight junction protein ZO-1 in dextran sulfate sodium induced colitis. J Surg Res 2007, 140:12-19

43. Moriez R, Salvador-Cartier C, Theodorou V, Fioramonti J, Eutamene $\mathrm{H}$, Bueno L: Myosin light chain kinase is involved in lipopolysaccharide-induced disruption of colonic epithelial barrier and bacterial translocation in rats. Am J Pathol 2005, 167:1071-1079

44. Schmitt M, Klonowski-Stumpe H, Eckert M, Luthen R, Haussinger D: Disruption of paracellular sealing is an early event in acute caerulein-pancreatitis. Pancreas 2004, 28:181-190

45. Gassler N, Rohr C, Schneider A, Kartenbeck J, Bach A, Obermuller $\mathrm{N}$, Otto HF, Autschbach F: Inflammatory bowel disease is associated with changes of enterocytic junctions. Am J Physiol Gastrointest Liver Physiol 2001, 281:G216-G228

46. Jankowski JA, Bedford FK, Boulton RA, Cruickshank N, Hall C, Elder J, Allan R, Forbes A, Kim YS, Wright NA, Sanders DS: Alterations in classical cadherins associated with progression in ulcerative and Crohn's colitis. Lab Invest 1998, 78:1155-1167

47. Kucharzik T, Walsh SV, Chen J, Parkos CA, Nusrat A: Neutrophi transmigration in inflammatory bowel disease is associated with differential expression of epithelial intercellular junction proteins. Am J Pathol 2001, 159:2001-2009

48. Schmitz H, Barmeyer C, Fromm M, Runkel N, Foss HD, Bentzel CJ, Riecken EO, Schulzke JD: Altered tight junction structure contributes to the impaired epithelial barrier function in ulcerative colitis. Gastroenterology 1999, 116:301-309

49. de Boer WI, Sharma HS, Baelemans SM, Hoogsteden HC, Lambrecht BN, Braunstahl GJ: Altered expression of epithelial junctional proteins in atopic asthma: possible role in inflammation. Can J Physiol Pharmacol 2008, 86:105-112

50. Hermiston ML, Gordon JI: Inflammatory bowel disease and adenomas in mice expressing a dominant negative $\mathrm{N}$-cadherin. Science 1995, 270:1203-1207

51. Muise AM, Walters $T$, Wine E, Griffiths AM, Turner D, Duerr RH, Regueiro MD, Ngan BY, Xu W, Sherman PM, Silverberg MS, Rotin D: Protein-tyrosine phosphatase sigma is associated with ulcerative colitis. Curr Biol 2007, 17:1212-1218

52. Laukoetter MG, Nava P, Lee WY, Severson EA, Capaldo CT, Babbin BA, Williams IR, Koval M, Peatman E, Campbell JA, Dermody TS, Nusrat A, Parkos CA: JAM-A regulates permeability and inflammation in the intestine in vivo. J Exp Med 2007, 204:3067-3076

53. Vetrano S, Rescigno M, Cera MR, Correale C, Rumio C, Doni A, Fantini M, Sturm A, Borroni E, Repici A, Locati M, Malesci A, Dejana $\mathrm{E}$, Danese S: Unique role of junctional adhesion molecule-a in main- taining mucosal homeostasis in inflammatory bowel disease. Gastroenterology 2008, 135:173-184

54. Madara JL, Moore R, Carlson S: Alteration of intestinal tight junction structure and permeability by cytoskeletal contraction. Am J Physiol 1987, 253:C854-C861

55. Utech M, Ivanov Al, Samarin SN, Bruewer M, Turner JR, Mrsny RJ, Parkos CA, Nusrat A: Mechanism of IFN- $\gamma$-induced endocytosis of tight junction proteins: myosin II-dependent vacuolarization of the apical plasma membrane. Mol Biol Cell 2005, 16:5040-5052

56. Youakim A, Ahdieh M: Interferon- $\gamma$ decreases barrier function in T84 cells by reducing ZO-1 levels and disrupting apical actin. Am $J$ Physiol 1999, 276:G1279-G1288

57. Su B, Ceponis PJ, Sherman PM: Cytoskeletal rearrangements in gastric epithelial cells in response to Helicobacter pylori infection. J Med Microbiol 2003, 52:861-867

58. Bouvry D, Planes C, Malbert-Colas L, Escabasse V, Clerici C: Hypoxia-induced cytoskeleton disruption in alveolar epithelia cells. Am J Respir Cell Mol Biol 2006, 35:519-527

59. Boland S, Boisvieux-Ulrich E, Houcine O, Baeza-Squiban A, Pouchelet M, Schoevaert D, Marano F: TGF- $\beta 1$ promotes actin cytoskeleton reorganization and migratory phenotype in epithelial tracheal cells in primary culture. J Cell Sci 1996, 109:2207-2219

60. Riegler M, Lotz M, Sears C, Pothoulakis C, Castagliuolo I, Wang CC Sedivy R, Sogukoglu T, Cosentini E, Bischof G, Feil W, Teleky B, Hamilton G, LaMont JT, Wenzl E: Bacteroides fragilis toxin 2 damages human colonic mucosa in vitro. Gut 1999, 44:504-510

61. Moser LA, Carter M, Schultz-Cherry S: Astrovirus increases epithelial barrier permeability independently of viral replication. J Viro 2007, 81:11937-11945

62. Isowa N, Liu M: Role of LPS-induced microfilament depolymerization in MIP-2 production from rat pneumocytes. Am J Physiol Lung Cel Mol Physiol 2001, 280:L762-L770

63. Oshitani N, Watanabe K, Nakamura S, Fujiwara Y, Higuchi K, Arakawa T: Dislocation of tight junction proteins without F-actin disruption in inactive Crohn's disease. Int J Mol Med 2005, 15:407-410

64. Keshavarzian A, Banan A, Farhadi A, Komanduri S, Mutlu E, Zhang $Y$, Fields JZ: Increases in free radicals and cytoskeletal protein oxidation and nitration in the colon of patients with inflammatory bowel disease. Gut 2003, 52:720-728

65. Werner T, Haller D: Intestinal epithelial cell signalling and chronic inflammation: from the proteome to specific molecular mechanisms Mutat Res 2007, 622:42-57

66. Vicente-Manzanares M, Ma X, Adelstein RS, Horwitz AR: Non-muscle myosin II takes centre stage in cell adhesion and migration. Nat Rev Mol Cell Biol 2009, 10:778-790

67. Ivanov Al, Bachar M, Babbin BA, Adelstein RS, Nusrat A, Parkos CA A unique role for nonmuscle myosin heavy chain IIA in regulation of epithelial apical junctions. PLoS ONE 2007, 2:e658

68. Ivanov Al, McCall IC, Parkos CA, Nusrat A: Role for actin filament turnover and a myosin II motor in cytoskeleton-driven disassembly of the epithelial apical junctional complex. Mol Biol Cell 2004 15:2639-2651

69. Dudek SM, Jacobson JR, Chiang ET, Birukov KG, Wang P, Zhan X Garcia JG: Pulmonary endothelial cell barrier enhancement by sphingosine 1-phosphate: roles for cortactin and myosin light chain kinase. J Biol Chem 2004, 279:24692-24700

70. Papakonstanti EA, Stournaras C: Cell responses regulated by early reorganization of actin cytoskeleton. FEBS Lett 2008, 582:2120-2127

71. Ivanov AI, Samarin SN, Bachar M, Parkos CA, Nusrat A: Protein kinase $\mathrm{C}$ activation disrupts epithelial apical junctions via ROCK-I dependent stimulation of actomyosin contractility. BMC Cell Biol 2009, 10:36

72. Heijink $I H$, Postma DS, Noordhoek JA, Broekema M, Kapus A House dust mite-promoted epithelial-to-mesenchymal transition in human bronchial epithelium. Am J Respir Cell Mol Biol 2010, 42:69-79

73. Babbin BA, Koch S, Bachar M, Conti MA, Parkos CA, Adelstein RS, Nusrat A, Ivanov AI: Non-muscle myosin IIA differentially regulates intestinal epithelial cell restitution and matrix invasion. Am J Pathol 2009, 174:436-448

74. Sandquist JC, Swenson KI, Demali KA, Burridge K, Means AR: Rho kinase differentially regulates phosphorylation of nonmuscle myosin II isoforms A and B during cell rounding and migration. J Biol Chem 2006, 281:35873-35883 
75. Conti MA, Even-Ram S, Liu C, Yamada KM, Adelstein RS: Defects in cell adhesion and the visceral endoderm following ablation of nonmuscle myosin heavy chain II-A in mice. J Biol Chem 2004, 279:41263-41266

76. Matsumura F: Regulation of myosin II during cytokinesis in higher eukaryotes. Trends Cell Biol 2005, 15:371-377

77. Beningo KA, Hamao K, Dembo M, Wang YL, Hosoya H: Traction forces of fibroblasts are regulated by the Rho-dependent kinase but not by the myosin light chain kinase. Arch Biochem Biophys 2006, 456:224-231

78. Smith A, Bracke M, Leitinger B, Porter JC, Hogg N: LFA-1-induced $T$ cell migration on ICAM-1 involves regulation of MLCK-mediated attachment and ROCK-dependent detachment. J Cell Sci 2003, 116:3123-3133

79. Samarin SN, Ivanov AI, Flatau G, Parkos CA, Nusrat A: Rho/Rhoassociated kinase-II signaling mediates disassembly of epithelial apical junctions. Mol Biol Cell 2007, 18:3429-3439

80. Bruewer M, Hopkins AM, Hobert ME, Nusrat A, Madara JL: RhoA. Rac1, and Cdc42 exert distinct effects on epithelial barrier via selective structural and biochemical modulation of junctional proteins and F-actin, Am J Physiol Cell Physiol 2004, 287:C327-C335

81. Sahai E, Marshall CJ: ROCK and Dia have opposing effects on adherens junctions downstream of Rho. Nat Cell Biol 2002, 4:408-415

82. Flynn AN, Buret AG: Tight junctional disruption and apoptosis in an in vitro model of Citrobacter rodentium infection. Microb Pathog 2008, 45:98-104

83. McKenzie JA, Ridley AJ: Roles of Rho/ROCK and MLCK in TNF- $\alpha$ induced changes in endothelial morphology and permeability. J Cell Physiol 2007, 213:221-228

84. Segain JP, Raingeard de la Bletiere D, Sauzeau V, Bourreille A, Hilaret G, Cario-Toumaniantz C, Pacaud P, Galmiche JP, Loirand G: Rho kinase blockade prevents inflammation via nuclear factor $\kappa \mathrm{B}$ inhibition: evidence in Crohn's disease and experimental colitis. Gastroenterology 2003, 124:1180-1187

85. Meyer-Schwesinger C, Dehde S, von Ruffer C, Gatzemeier S, Klug P, Wenzel UO, Stahl RA, Thaiss F, Meyer TN: Rho kinase inhibition attenuates LPS-induced renal failure in mice in part by attenuation of NF- $\kappa$ B p65 signaling. Am J Physiol Renal Physiol 2009, 296:F1088-F1099

86. Fan L, Sebe A, Peterfi Z, Masszi A, Thirone AC, Rotstein OD, Nakano H, McCulloch CA, Szaszi K, Mucsi I, Kapus A: Cell contact-dependent regulation of epithelial-myofibroblast transition via the rho-rho kinase-phospho-myosin pathway. Mol Biol Cell 2007, 18:1083-1097

87. Masszi A, Fan L, Rosivall L, McCulloch CA, Rotstein OD, Mucsi I, Kapus A: Integrity of cell-cell contacts is a critical regulator of TGF- $\beta$ 1-induced epithelial-to-myofibroblast transition: role for $\beta$-catenin. Am J Pathol 2004, 165:1955-1967

88. Samarin S, Nusrat A: Regulation of epithelial apical junctional complex by Rho family GTPases. Front Biosci 2009, 14:1129-1142

89. Rubenstein NM, Callahan JA, Lo DH, Firestone GL: Selective glucocorticoid control of Rho kinase isoforms regulate cell-cell interactions. Biochem Biophys Res Commun 2007, 354:603-607

90. Buyukafsar K, Arikan O, Ark M, Kubat H, Ozveren E: Upregulation of Rho-kinase (ROCK-2) expression and enhanced contraction to endothelin-1 in the mesenteric artery from lipopolysaccharide-treated rats. Eur J Pharmacol 2004, 498:211-217

91. Matsuzawa T, Kuwae A, Yoshida S, Sasakawa C, Abe A: Enteropathogenic Escherichia coli activates the RhoA signaling pathway via the stimulation of GEF-H1. EMBO J 2004, 23:3570-3582

92. Fukazawa A, Alonso C, Kurachi K, Gupta S, Lesser CF, McCormick BA, Reinecker HC: GEF-H1 mediated control of NOD1 dependent NF $-\kappa \mathrm{B}$ activation by Shigella effectors, PLoS Pathog 2008, 4:e1000228

93. Benais-Pont G, Punn A, Flores-Maldonado C, Eckert J, Raposo G, Fleming TP, Cereijido M, Balda MS, Matter K: Identification of a tight junction-associated guanine nucleotide exchange factor that activates Rho and regulates paracellular permeability. J Cell Biol 2003, 160:729-740

94. Shen L, Black ED, Witkowski ED, Lencer WI, Guerriero V, Schneeberger EE, Turner JR: Myosin light chain phosphorylation regulates barrier function by remodeling tight junction structure. J Cell Sci 2006, 119:2095-2106

95. Al-Sadi R, Ye D, Dokladny K, Ma TY: Mechanism of IL-1 $\beta$-induced increase in intestinal epithelial tight junction permeability. J Immuno 2008, 180:5653-5661

96. Schwarz BT, Wang F, Shen L, Clayburgh DR, Su L, Wang Y, Fu YX Turner JR: LIGHT signals directly to intestinal epithelia to cause barrier dysfunction via cytoskeletal and endocytic mechanisms. Gastroenterology 2007, 132:2383-2394

97. Eutamene H, Theodorou V, Schmidlin F, Tondereau V, Garcia-Villar R, Salvador-Cartier C, Chovet M, Bertrand C, Bueno L: LPS-induced lung inflammation is linked to increased epithelial permeability: role of MLCK, Eur Respir J 2005, 25:789-796

98. Fedwick JP, Lapointe TK, Meddings JB, Sherman PM, Buret AG: Helicobacter pylori activates myosin light-chain kinase to disrupt claudin-4 and claudin-5 and increase epithelial permeability. Infect Immun 2005, 73:7844-7852

99. Philpott DJ, McKay DM, Mak W, Perdue MH, Sherman PM: Signal transduction pathways involved in enterohemorrhagic Escherichia coli-induced alterations in T84 epithelial permeability. Infect Immun 1998, 66:1680-1687

100. Scott KG, Meddings JB, Kirk DR, Lees-Miller SP, Buret AG: Intestinal infection with Giardia spp. reduces epithelial barrier function in a myosin light chain kinase-dependent fashion. Gastroenterology 2002, 123:1179-1190

101. Bain J, McLauchlan H, Elliott M, Cohen P: The specificities of protein kinase inhibitors: an update. Biochem J 2003, 371:199-204

102. Zolotarevsky Y, Hecht G, Koutsouris A, Gonzalez DE, Quan C, Tom J, Mrsny RJ, Turner JR: A membrane-permeant peptide that inhibits MLC kinase restores barrier function in in vitro models of intestinal disease. Gastroenterology 2002, 123:163-172

103. Feighery LM, Cochrane SW, Quinn T, Baird AW, O'Toole D, Owens SE, O'Donoghue D, Mrsny RJ, Brayden DJ: Myosin light chain kinase inhibition: correction of increased intestinal epithelial permeability in vitro. Pharm Res 2008, 25:1377-1386

104. Su L, Shen L, Clayburgh DR, Nalle SC, Sullivan EA, Meddings JB, Abraham C, Turner JR: Targeted epithelial tight junction dysfunction causes immune activation and contributes to development of experimental colitis. Gastroenterology 2009, 136:551-563

105. dos Remedios CG, Chhabra D, Kekic M, Dedova IV, Tsubakihara M, Berry DA, Nosworthy NJ: Actin binding proteins: regulation of cytoskeletal microfilaments. Physiol Rev 2003, 83:433-473

106. Theriot JA: The polymerization motor. Traffic 2000, 1:19-28

107. Ivanov Al, Hunt D, Utech M, Nusrat A, Parkos CA: Differential roles for actin polymerization and a myosin II motor in assembly of the epithelia apical junctional complex. Mol Biol Cell 2005, 16:2636-2650

108. Shen L, Turner JR: Actin depolymerization disrupts tight junctions via caveolae-mediated endocytosis. Mol Biol Cell 2005, 16:3919-3936

109. Haviv L, Gillo D, Backouche F, Bernheim-Groswasser A: A cytoskeletal demolition worker: myosin II acts as an actin depolymerization agent. J Mol Biol 2008, 375:325-330

110. Gunst SJ, Zhang W: Actin cytoskeletal dynamics in smooth muscle: a new paradigm for the regulation of smooth muscle contraction. Am J Physiol Cell Physiol 2008, 295:C576-C587

111. Le TL, Joseph SR, Yap AS, Stow JL: Protein kinase C regulates endocytosis and recycling of E-cadherin. Am J Physiol Cell Physio 2002, 283:C489-C499

112. Musch MW, Walsh-Reitz MM, Chang EB: Roles of ZO-1, occludin, and actin in oxidant-induced barrier disruption. Am J Physiol Gastrointest Liver Physiol 2006, 290:G222-G231

113. Geny B, Grassart A, Manich M, Chicanne G, Payrastre B, Sauvonnet N, Popoff MR: Rac1 inactivation by lethal toxin from Clostridium sordellii modifies Focal Adhesions upstream of actin depolymerization. Cell Microbiol 2010, 12:217-232

114. Ono S: Mechanism of depolymerization and severing of actin filaments and its significance in cytoskeletal dynamics. Int Rev Cytol 2007, 258:1-82

115. Sarmiere PD, Bamburg JR: Regulation of the neuronal actin cytoskeleton by ADF/cofilin. J Neurobiol 2004, 58:103-117

116. Bernard O: Lim kinases, regulators of actin dynamics. Int J Biochem Cell Biol 2007, 39:1071-1076

117. Huang TY, DerMardirossian C, Bokoch GM: Cofilin phosphatases and regulation of actin dynamics. Curr Opin Cell Biol 2006 18:26-31

118. Nagumo $Y$, Han J, Bellila A, Isoda H, Tanaka T: Cofilin mediates tight-junction opening by redistributing actin and tight-junction proteins. Biochem Biophys Res Commun 2008, 377:921-925 
119. Ashworth SL, Southgate EL, Sandoval RM, Meberg PJ, Bamburg JR, Molitoris BA: ADF/cofilin mediates actin cytoskeletal alterations in LLC-PK cells during ATP depletion. Am J Physiol Renal Physiol 2003, 284:F852-F862

120. Schwartz N, Hosford M, Sandoval RM, Wagner MC, Atkinson SJ, Bamburg J, Molitoris BA: Ischemia activates actin depolymerizing factor: role in proximal tubule microvillar actin alterations. Am J Physiol 1999, 276:F544-F551

121. Dai YP, Bongalon S, Tian H, Parks SD, Mutafova-Yambolieva VN, Yamboliev IA: Upregulation of profilin, cofilin-2 and LIMK2 in cultured pulmonary artery smooth muscle cells and in pulmonary arteries of monocrotaline-treated rats. Vascul Pharmacol 2006, 44:275-282

122. Gorovoy M, Han J, Pan H, Welch E, Neamu R, Jia Z, Predescu D, Vogel S, Minshall RD, Ye RD, Malik AB, Voyno-Yasenetskaya T: LIM kinase 1 promotes endothelial barrier disruption and neutrophil infiltration in mouse lungs. Circ Res 2009, 105:549-556

123. Verdoni AM, Smith RS, Ikeda A, Ikeda S: Defects in actin dynamics lead to an autoinflammatory condition through the upregulation of CXCL5. PLoS One 2008, 3:e2701

124. Ghosh M, Song X, Mouneimne G, Sidani M, Lawrence DS, Condeelis JS: Cofilin promotes actin polymerization and defines the direction of cell motility. Science 2004, 304:743-746

125. Revenu C, Athman R, Robine S, Louvard D: The co-workers of actin filaments: from cell structures to signals. Nat Rev Mol Cell Biol 2004, 5:635-646

126. Bartles JR: Parallel actin bundles and their multiple actin-bundling proteins. Curr Opin Cell Biol 2000, 12:72-78

127. Tilney LG, Connelly PS, Ruggiero L, Vranich KA, Guild GM: Actin filament turnover regulated by cross-linking accounts for the size, shape, location, and number of actin bundles in Drosophila bristles. Mol Biol Cell 2003, 14:3953-3966

128. Abe K, Takeichi M: EPLIN mediates linkage of the cadherin catenin complex to F-actin and stabilizes the circumferential actin belt. Proc Natl Acad Sci USA 2008, 105:13-19
129. Schultheiss T, Choi J, Lin ZX, DiLullo C, Cohen-Gould L, Fischman $\mathrm{D}$, Holtzer $\mathrm{H}$ : A sarcomeric $\alpha$-actinin truncated at the carboxyl end induces the breakdown of stress fibers in PtK2 cells and the formation of nemaline-like bodies and breakdown of myofibrils in myotubes. Proc Natl Acad Sci USA 1992, 89:9282-9286

130. Nakatsuji $H$, Nishimura N, Yamamura R, Kanayama HO, Sasaki T: Involvement of actinin-4 in the recruitment of JRAB/MICAL-L2 to cell-cell junctions and the formation of functional tight junctions. Mol Cell Biol 2008, 28:3324-3335

131. Grimm-Gunter EM, Revenu C, Ramos S, Hurbain I, Smyth N, Ferrary E, Louvard D, Robine S, Rivero F: Plastin 1 binds to keratin and is required for terminal web assembly in the intestinal epithelium. Mo Biol Cell 2009, 20:2549-2562

132. Kaplan JM, Kim SH, North KN, Rennke H, Correia LA, Tong HQ, Mathis BJ, Rodriguez-Perez JC, Allen PG, Beggs AH, Pollak MR: Mutations in ACTN4, encoding $\alpha$-actinin-4, cause familial focal segmental glomerulosclerosis. Nat Genet 2000, 24:251-256

133. Kos CH, Le TC, Sinha S, Henderson JM, Kim SH, Sugimoto H, Kalluri R, Gerszten RE, Pollak MR: Mice deficient in $\alpha$-actinin- 4 have severe glomerular disease. J Clin Invest 2003, 111:1683-1690

134. Orso E, Moehle C, Boettcher A, Szakszon K, Werner T, Langmann T, Liebisch G, Buechler C, Ritter M, Kronenberg F, Dieplinger H, Bornstein SR, Stremmel W, Schmitz G: The satiety factor apolipoprotein A-IV modulates intestinal epithelial permeability through its interaction with $\alpha$-catenin: implications for inflammatory bowel diseases. Horm Metab Res 2007, 39:601-611

135. Izaguirre G, Aguirre L, Hu YP, Lee HY, Schlaepfer DD, Aneskievich BJ, Haimovich B: The cytoskeletal/non-muscle isoform of alphaactinin is phosphorylated on its actin-binding domain by the focal adhesion kinase. J Biol Chem 2001, 276:28676-28685

136. Han MY, Kosako H, Watanabe T, Hattori S: Extracellular signalregulated kinase/mitogen-activated protein kinase regulates actin organization and cell motility by phosphorylating the actin crosslinking protein EPLIN. Mol Cell Biol 2007, 27:8190-8204 